\title{
Differential Scanning Calorimetric Study of Enthalpy Relaxation in Polystyrene, Poly(4-hydroxystyrene), and Their Copolymers
}

\author{
Hirohisa Yoshida, Kunio NAKAmURA,* and Yasuji KobaYASHI \\ Department of Industrial Chemistry, Faculty of Technology, \\ Tokyo Metropolitan University, \\ Fukazawa, Setagaya-ku, Tokyo 158, Japan \\ *Industrial Research Institute of Kanagawa Prefecture, \\ Showa-machi, Kanazawa-ku, Yokohama, 236
}

(Received May 22, 1982)

\begin{abstract}
Enthalpy relaxation in polystyrene, poly(4-hydroxystyrene), and styrene/4hydroxystyrene copolymers were studied by differential scanning calorimetry. It was found that the relaxation time strongly depends on the content of hydroxystyrene in the polymer. This phenomenon may be ascribed to the formation of hydrogen bonds between hydroxyl groups which act to restrict the segmental motion of the main chain. It was also found that the enthalpy relaxation of poly(4-hydroxystyrene) and hydroxystyrene-rich copolymers are promoted by the presence of a small amount of absorbed water.
\end{abstract}

KEY WORDS Styrene-Hydroxystyrene Copolymer / Polystyrene / Enthalpy Relaxation / Hydrogen Bond / Sorption / Differential Scanning Calorimetry /

It is well known that a polymeric glass obtained by rapid cooling is in a nonequilibrium state which has excess thermodynamic quantities in enthalpy and volume. When this polymeric glass is annealed at temperatures below the glass transition temperature $\left(T_{\mathrm{g}}\right)$, the excess enthalpy and volume relax toward those of the more stable state. ${ }^{1-9}$ This is known as enthalpy or volume relaxation. With decreasing excess thermodynamic quantities, polymeric glasses become less ductile and more brittle. $^{10-12}$

Previous investigation ${ }^{6,7,13,14}$ showed that enthalpy relaxation accompanying the annealing of a polymeric glass at temperatures below $T_{\mathrm{g}}$ is caused by restriction of the segmental motion of the main chain. In our previous paper, ${ }^{15}$ the synthesis and the thermal properties of a series of amorphous styrene/ 4-hydroxystyrene copolymers were described. In these copolymers, the number of hydrogen bonds formed changed with the copolymer content. It was clarified that hydrogen bonds restricted the molecular motion of the main chain and were broken by absorbed water. The primary purpose of this study has been to examine how the hydrogen bonds formed between hydroxyl groups in these copolymers restrict the motion of the main chain and thereby retard the enthalpy relaxation.

\section{EXPERIMENTAL}

\section{Samples}

The samples used were polystyrene (PS), poly(4hydroxystyrene) (PHS), and random styrene/4hydroxystyrene copolymers of various composition and were prepared according to the method in our previous paper. ${ }^{15}$

The flake-like samples were pressed at $300 \mathrm{~kg}$ $\mathrm{cm}^{-2}$ at room temperature in a vacuum hotpress. The films obtained were about $1 \mathrm{~mm}$ thick.

\section{Measurements}

Perkin-Elmer differential scanning calorimeters, Model DSC 1B and DSC II, were used to anneal the samples and measure their heat capacity, respectively. Sample weights were about $10-20 \mathrm{mg}$. The heat capacity was measured at a heating rate of 10 
$\mathrm{K} \min ^{-1}$.

The effects of thermal history were eliminated by heating the samples to a temperature of about $30 \mathrm{~K}$ above $T_{\mathrm{g}}$ before annealing. After this, each sample was cooled to the annealing temperature at a rate of $16 \mathrm{~K} \mathrm{m^{-1 }}$ and was immediately subjected to a heat capacity measurement. Both DSC measurements and annealing were carried out in a nitrogen atmosphere.

X-Ray diffractograms of the samples were obtained with a Rigaku Denki Model RU-3 diffractometer provided with a proportional counter. Gel permeation chromatograms of the samples were obtained with a Toyo Soda high speed liquid chromatograph Model HLC $801 \mathrm{~A}$, using a column set consisting of four Toyo Soda Styrogel columns, $10^{5}$, $10^{5}, 10^{4}$, and $10^{3} \AA$ calibrated with standard polystyrene samples (Pressure Chemical). The weightaverage molecular weight $M_{w}$ of PHS and the copolymers was estimated from the calibration lines established with standard polystyrene. The flow rate was $1 \mathrm{ml} \mathrm{min} .^{-1}$ Tetrahydrofran (THF) was used as the eluting solvent. Infrared spectra of the samples were obtained with a Hitachi Model 285 graing spectrophotometer.

\section{RESULTS AND DISCUSSION}

The X-ray diffractograms of the samples showed typical amorphous patterns. The DSC curves of the samples showed no characteristic change except for a glass transition between room and the decomposition temperature.

Table I summarizes the values of $M_{w}, M_{w} / M_{n}\left(M_{n}\right.$ is the number-average molecular weight also estimated from GPC), $T_{\mathrm{g}}$ and $\Delta C_{\mathrm{p}}$ of the samples examined. Here, $\Delta C_{\mathrm{p}}$ stands for the heat capacity difference between the glassy and liquid states. The copolymer composition, mol percent of the 4-hydroxystyrene monomer in the table were calculated from the fed monomer ratio and also from the relative intensity of the $3400 \mathrm{~cm}^{-1}$ and $2850 \mathrm{~cm}^{-1}$ infrared bands. The values determined by the two methods agreed closely.

\section{Glass Transition Behavior}

Figure 1 shows $T_{\mathrm{g}}$ of the samples plotted against the 4-hydroxystyrene (HS) composition. The solid line in the figure was calculated from Wood's relation for random copolymers ${ }^{16}$ :
Table I. Sample characterization and thermal analysis data

\begin{tabular}{|c|c|c|c|c|}
\hline \multirow{2}{*}{$\begin{array}{l}\text { HS content } \\
\quad\left(\mathrm{mol}^{\circ} \mathrm{o}\right)\end{array}$} & \multirow{2}{*}{$M_{n}{ }^{\mathrm{a}}$} & \multirow{2}{*}{$M_{w} / M_{n}^{\mathrm{b}}$} & \multirow{2}{*}{$\frac{T_{\mathrm{g}}}{\mathrm{K}}$} & \multirow{2}{*}{$\frac{\Delta C_{\mathrm{p}}^{\mathrm{c}}}{\mathrm{Jg}^{-1}}$} \\
\hline & & & & \\
\hline 0 & $5.4 \times 10^{4}$ & 2.1 & 368.0 & 0.314 \\
\hline 25 & $2.9 \times 10^{4}$ & 2.3 & 380.5 & 0.306 \\
\hline 35 & $3.4 \times 10^{4}$ & 2.5 & 383.0 & 0.307 \\
\hline 48 & $4.7 \times 10^{4}$ & 2.9 & 393.2 & 0.306 \\
\hline 70 & $6.9 \times 10^{4}$ & 3.8 & 419.3 & 0.309 \\
\hline 77 & $4.8 \times 10^{4}$ & 3.4 & 425.3 & 0.310 \\
\hline 100 & $7.2 \times 10^{4}$ & 4.9 & 443.4 & 0.303 \\
\hline
\end{tabular}

a,b Average molecular weight and polydisperse indices $\left(M_{w} / M_{n}\right)$ estimated by GPC.

c Heat capacity difference $\Delta C_{\mathrm{p}}$, between the liquid and glassy states determined from DSC curves.

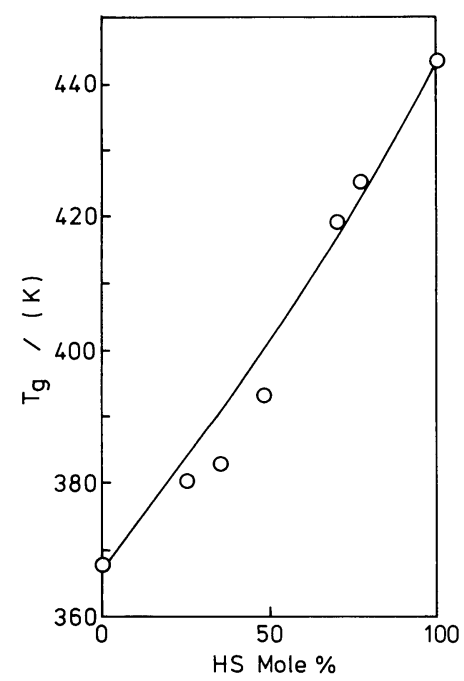

Figure 1. Glass transition temperature $T_{\mathrm{g}}$ as a function of HS content. The solid line represents eq 1 .

$$
T_{\mathrm{g}}^{-1}=(1-\alpha) T_{\mathrm{g} 1}^{-1}+\alpha T_{\mathrm{g} 2}^{-1}
$$

where $T_{\mathrm{g} 1}$ and $T_{\mathrm{g} 2}$ represent the glass transition temperatures of the first and second components constituting the copolymer and $\alpha$ is the composition of the second component. It can been seen that the measured $T_{\mathrm{g}}$ agrees well with eq 1 at high $\mathrm{HS}$ content, but is below the values calculated by eq 1 at low HS content. Similar results have been reported for $T_{\mathrm{g}}$ of polyamides (nylon 3 -nylon 13). ${ }^{17}$ The fact that PHS has a $T_{\mathrm{g}}$ higher than PS may be explained as resulting from hydrogen bond for- 


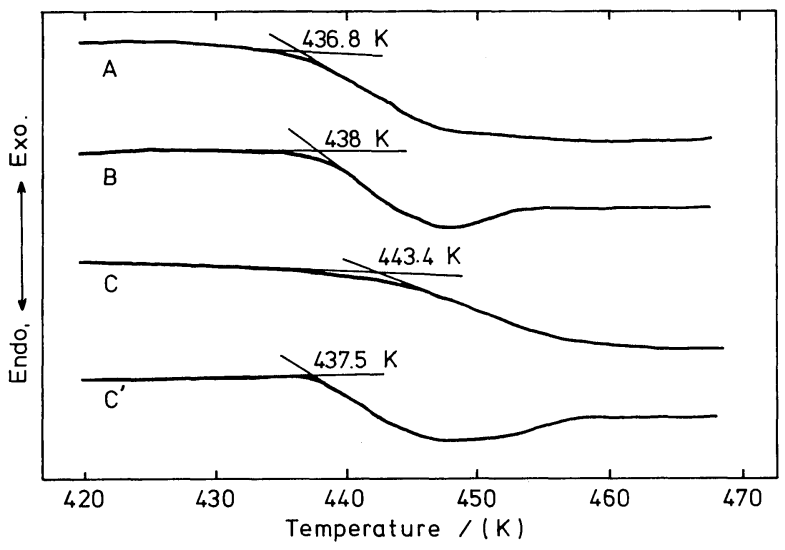

Figure 2. DSC curves of PHS having different thermal history: A, cooled from $460 \mathrm{~K}$ at $16 \mathrm{~K} \mathrm{~min}^{-1}$; $\mathrm{B}$, cooled from $460 \mathrm{~K}$ at $0.5 \mathrm{~K} \mathrm{~min}^{-1} ; \mathrm{C}$, cooled from $500 \mathrm{~K}$ at $0.5 \mathrm{~K} \mathrm{~min}^{-1} ; \mathrm{C}^{\prime}$, cooled from $460 \mathrm{~K}$ at 0.5 $\mathrm{K} \mathrm{min}^{-1}$ after water-absorbed under $100 \%$ relative humidity. DSC heating rate is $16 \mathrm{~K} \mathrm{~min}^{-1}$.

mation between HS monomers. Thus, the change in $T_{\mathrm{g}}$ shown in Figure 1 may be primarily attributed to an enhanced formation of hydrogen bonds with an increase in HS content in the copolymer.

\section{DSC Behavior}

Figure 2 shows the DSC curves of PHS having different thermal histories. Thus, curves $\mathrm{A}$ and $\mathrm{B}$ were obtained with samples glassified from $460 \mathrm{~K}$ at cooling rates of 16 and $0.5 \mathrm{~K} \mathrm{~min}^{-1}$, respectively. The former showed only a step change in $C_{\mathrm{p}}$ at the glass transition, while the latter exhibited an additional endothermic peak. Curve $\mathrm{C}$ was determined with the sample initially equilibrated under $100 \%$ relative humidity for one week and then cooled at a rate of $0.5 \mathrm{~K} \mathrm{~min}^{-1}$ from $500 \mathrm{~K}$. For obtaining curve $\mathrm{C}^{\prime}$ the water-absorbed sample was cooled at the same rate from $460 \mathrm{~K}$. Note that curve $C^{\prime}$ shows an endothermic peak very similar to that of curve $B$.

Our recent thermogravimetric study ${ }^{18}$ showed that "bound" water as well as "free" water in waterabsorbed PHS can be removed when a sample is heated to a temperature in the range from 480 to $500 \mathrm{~K}$. Therefore, the fact that curve $\mathrm{C}$ exhibits no endothermic peak may be attributed to the complete removal of "bound" water from the sample. For the following experiments, we used waterabsorbed PHS and the $77 \%$ copolymer prepared in the same way as sample $\mathrm{C}^{\prime}$. The $T_{\mathrm{g}}$ of waterabsorbed samples was about $438 \mathrm{~K}$ for PHS and $422 \mathrm{~K}$ for the $77 \%$ copolymer.

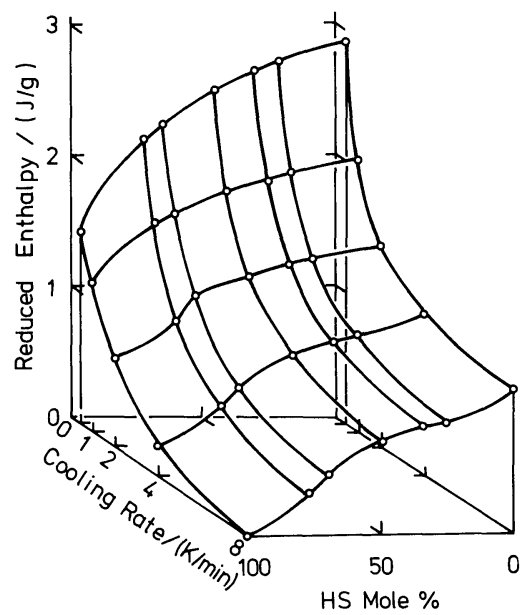

Figure 3. Three-dimensional illustration of the reduced enthalpy as a function of HS content and cooling rate.

\section{Effects of Cooling Rate}

In order to examine the effect of the cooling rate on the glass formation, the following experiment was performed. A given sample was cooled from $\left(T_{\mathrm{g}}+30 \mathrm{~K}\right)$ to $\left(T_{\mathrm{g}}-30 \mathrm{~K}\right)$ at various rates from 0.5 to $8 \mathrm{~K} \mathrm{~min} \min ^{-1}$, and its heat capacity $\left(C_{\mathrm{p}}\right)$ was measured immediately after cooling. The same operation was repeated with a quenched sample. The reduced enthalpy was calculated from the $C_{\mathrm{p}}$ data thus obtained as the difference in enthalpy between the quenched sample and the sample cool- 
ed at a given rate. The results obtained for different cooling rates and HS content are illustrated three dimensionally in Figure 3.

It is well known that the glassy state depends on the cooling velocity from the liquid state. ${ }^{19,20}$ Isothermal enthalpy relaxation occurs at temperatures just below $T_{\mathrm{g}}$, with the enthalpy decreasing sharply at the initial stage. When a sample is cooled through the range of these temperatures at a rate slower than the relaxation rate, the enthalpy relaxation may be observed experimentally, and a consecutive heating DSC run will exhibit an endothermic peak due to energy absorption by enthalpy relaxation. Figure 3 can be taken as representing the effect of HS content on this enthalpy relaxation in our copolymer. It can be seen that the reduced enthalpy is larger than that of PHS at any cooling rate examined, implying that the enthalpy relaxation in PS proceeds at a rate faster than in PHS. This difference may be explained as a result of hydrogen bond formation in PHS which should hinder the thermal motion of the chain and thus retard the relaxation.

\section{Excess Enthalpy}

The excess enthalpy $\Delta H_{\mathrm{t}}$ was estimated using a modification of Lagasse's method ${ }^{21}$ described in our recent paper. ${ }^{14}$ In Figure $4, \Delta H_{\mathrm{t}}$ is plotted against the annealing period of time. The annealing temperatures $T_{\mathrm{a}}$ were chosen at $10 \mathrm{~K}$ below $T_{\mathrm{g}}$, being $358,371,383,412$, and $428 \mathrm{~K}$ for HS contents of 0 , $0.25,0.48,0.77$, and 1 , respectively. Figure 4 indicates that the rate of enthalpy relaxation decreases as the HS content is increased for any annealing period of time examined.

If the enthalpy relaxation at $T_{\mathrm{a}}$ follows a single exponential curve, $\Delta H_{\mathrm{t}}$ may be represented by

$$
\Delta H_{\mathrm{t}}=\Delta H_{0} \exp (-t / \tau)
$$

where $\tau$ is the relaxation time and $\Delta H_{0}$ is the excess enthalpy of a quenched sample. However, in some previous studies, it was found that both volume and enthalpy relaxations, particularly at the initial stage, could not be described by a single exponential as in eq 2. ${ }^{5,22}$ Thus, eq 2 may be only an approximation to $\Delta H_{\mathrm{t}}$, but the relaxation time calculated by substituting $t$ for $\Delta H_{\mathrm{t}} / \Delta H_{0}=0.5$ into this equation may be useful for comparison. This apparent relaxation time is denoted by $\tau_{1 / 2}$.

Figure 5 shows $\tau_{1 / 2}$ plotted against the HS con-

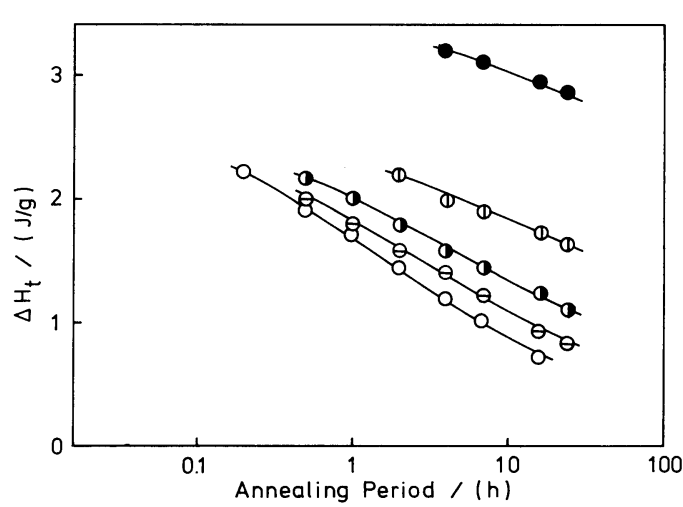

Figure 4. Excess enthalpy plotted against annealing period of time for PS (O), PHS ( $)$, and copolymers of HS contents $25 \%(\Theta), 48 \%(\odot)$, and $77 \%$ (1).

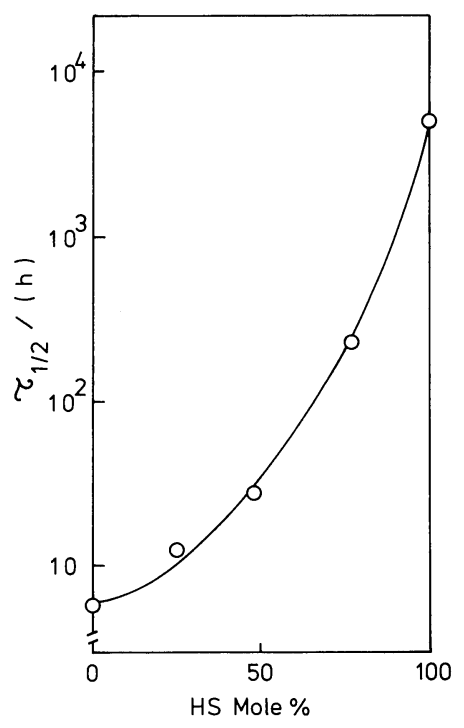

Figure 5. Apparent relaxation time $\tau_{1 / 2}$ plotted against HS content.

tent in the copolymer. Note that all the values of $\tau_{1 / 2}$ shown correspond to the same $T_{\mathrm{g}}-T_{\mathrm{a}}$, i.e., $T_{\mathrm{a}}$ being $10 \mathrm{~K}$ below $T_{\mathrm{g}}$ of the respective samples. It can be seen that the relaxation time differs markedly for different samples. For HS content below $50 \%$, the change in $\tau_{1 / 2}$ with HS content is rather moderate, but is quite appreciable at HS content above $50 \%$. On the basis of our previous study ${ }^{15}$ and the $T_{\mathrm{g}}$ data shown in Figure 1, this increase in $\tau_{1 / 2}$ with HS content may be interpreted as due to an increase in the formation of hydrogen bonds between hydroxyl groups in the copolymer. 


\section{Enthalpy Relaxation and Segmental Motion}

Our previous studies on the enthalpy relaxation of poly(alkyl methacrylate) $\mathbf{s}^{13}$ and polystyrene $\mathrm{e}^{14}$ suggest that this relaxation process is associated with the segmental motion of the main chain, and demonstrate that the relaxation time increases in the presence of substituent groups such as the $\alpha$-methyl group which hinders the thermal motion of the main chain. In our copolymer, hydrogen bonds formed between hydroxyl groups should restricted the motion of styrene monomer and non-hydrogen bonded HS monomer sequences. It is evident that as the HS content increases, the restriction becomes greater, causing the enthalpy relaxation to occur more slowly.

Quite recently, Nakamura et al. ${ }^{23}$ found a close correlation between the $T_{\mathrm{g}}$ of our copolymer and the fraction of hydrogen-bonded hydroxyl groups. According to this relation, $60-70 \%$ of the hydroxyl groups in dry PHS $\left(T_{\mathrm{g}}=443 \mathrm{~K}\right)$ are in the hydrogenbonded state. This figure indicates that the thermal motion of the main chain in dry PHS must be almost entirely restricted. The corresponding figure in water-absorbed PHS $\left(T_{\mathrm{g}}=438 \mathrm{~K}\right)$ is $50-60 \%$, suggesting that segmental motion involving one or two repeating units can take place. The fractions of hydrogen-bonded hydroxyl groups are 40, 25, and $10 \%$ for HS content of $0.77\left(T_{\mathrm{g}}=422 \mathrm{~K}\right), 0.48\left(T_{\mathrm{g}}=\right.$ $393 \mathrm{~K})$, and $0.10\left(T_{\mathrm{g}}=381 \mathrm{~K}\right)$, respectively.

Doing on the assumption of the randomness of monomer sequences and of hydrogen bond formation, the average number of repeating units between hydrogen bonds may be estimated to be 8 for our copolymer with an HS content of 0.48 . Hence, in the range of HS content above 0.5 , it is quite likely that the occurrence of segmental motion involving about 10 repeating units is largely restricted, since, in polymeric glasses, hydrogen bonds act as cross-linkages. Thus, at such a high HS content, enthalpy relaxation in our copolymer should proceed as a result of a cooperative motion of a few consecutive repreating units.
Acknowledgement. The authors are grateful to Dr. H. Hatakeyama, Industrial Products Institute, for his helpful comments.

\section{REFERENCES}

1. R. Straff and D. R. Uhlmann, J. Polym. Sci., Polym. Phys. Ed., 14, 1087 (1976).

2. A. J. Kovacs, J. Polym. Sci., 30, 131 (1958).

3. A. J. Kovacs, Forschr. Hochpolym. Forsch., 3, 394 (1963).

4. M. Uchidoi, M. Hattori, K. Adachi, and Y. Ishida, Plastic Industry News, 20, 129 (1974).

5. M. Uchidoi, K. Adachi, and Y. Ishida, Polym. J., 10, 161 (1978).

6. S. E. B. Petrie, J. Polym. Sci., A-2, 10, 1255 (1972).

7. A. S. Marshall and S. E. B. Petrie, J. Appl. Phys., 46, 4223 (1975).

8. S. E. B. Petrie, J. Macromol. Sci. Phys., B12, 225 (1976).

9. H.) tt, Colloid Polym. Sci., 257, 486 (1979).

10. L. C. E. Struik, "Physical Aging in Amorphous Polymers and Other Materials," Elsevier, Amsterdam, 1978.

11. K. Neki and P. H. Geil, J. Macromol. Sci. Phys., B8, 295 (1973).

12. R. M. Minini, R. S. Moore, J. R. Flick, and S. E. B. Petrie, J. Macromol. Sci. Phys., B8, 343 (1973).

13. H. Yoshida and Y. Kobayashi, J. Macromol. Sci. Phys., in press (1982).

14. H. Yoshida and Y. Kobayashi, Sen-i Gakkaishi, 37, T-458 (1981).

15. K. Nakamura, T. Hatakeyama, and H. Hatakeyama, Kobunshi Ronbunshu, 38, 763 (1981).

16. L. A. Wood, J. Polym. Sci., 28, 319 (1958).

17. J. Brandrup and E. H. Immergut, "Polymer Handbood," Vol. III, J. Willy \& Sons, New York, p. 168 .

18. K. Nakamura, T. Hatakeyama, and H. Hatakeyama, Polym. Prepr. Jpn., 30, 506 (1981).

19. B. Wunderlich, D. M. Bodily, and M. H. Kaplan, $J$. Appl. Phys., 35, 95 (1964).

20. R. O. Davies and G. O. Jones, Adv. Phys., 2, 370 (1953).

21. R. R. Lagasse, J. Polym. Sci., Polym. Lett. Ed., 18, 357 (1980).

22. K. Adachi, H. Suga and S. Seki, Bull. Chem. Soc. Jpn., 44, 78 (1971).

23. K. Nakamura, T. Hatakeyama, and H. Hatakeyama, Kobunshi Ronbunshu, 39, 53 (1982). 